論文

항공기의 횡방향 접근 제어를 위한 축소차수 상태관측기 설계

이병석*, 허문범*, 남기욱*, 박형택**

\title{
Reduced Order Luenberger State Observer Design for Lateral Direction Approach Control of Aircraft
}

ByungSeok Lee*, Moon-Beom Heo*, Gi-Wook Nam* and Hyeong-Taek Park**

\begin{abstract}
The availability of the GPS signal has been expanded greatly in the field of society overall through the development and construction of the GNSS(Global Navigation Satellite System). Furthermore, in the military, aviation and field of space, the GPS signal is applied widely through the combination of INS consisting of gyroscope and accelerometer, IMU, AHRS with the addition of magnetic sensor. Particularly, the performance of these equipments or sensors is very important with GPS and PAR(Precision Approach Radar) in the flight control of the aircraft. This paper deals with MATLAB simulation and ROLSO(Reduced Order Luenberger State Observer) design to reduce the load of system and realize the stable lateral direction approach control in an appropriate time for reduction of the horizontal error which is importantly considered while an aircraft lands instead of the FOLSO(Full Order Luenberger State Observer) using all measurement values. Consequently, ROLSO is expected to be used for the aircraft's attitude control in the aircraft landing causing the burden to the pilots.
\end{abstract}

Key Words : GNSS(위성항법시스템), GPS(위성항법장치), INS(관성항법시스템), $\mathrm{IMU(관성}$ 측정장치), AHRS(자세측정장치), Lateral Direction Approach(횡방향 접근), PAR(정밀접근레 이다), $\mathrm{FOLSO}$ (전차수 상태관측기), $\mathrm{ROLSO}$ (축소차수 상태관측기)

\section{I. 서 론}

현대의 항공기 제어 기술은 전자적인 인터페 이스에 의한 FBW(Fly-By-Wire) 제어 시스템이 수동제어(manual flight control)를 대신하고 있 다. 이에 더 나아가 비행 제어 소프트웨어를 업

2012년 04월 30일 접수 2012년 05월 15일 심사완료 논문심사일 (2012.05.02 1차), (2012.05.15, 2차)

* 한국항공우주연구원

** 인하대학교

연락저자, E-mail : bslee@kari.re.kr 대전광역시 유성구 과학로 169-84 한국항공우주연구원 교통. 항법기술연구센터 위성항법팀
그레이드하여 비행 특성을 분석하고 자기학습을 할 수 있는 신경망 기술을 구현한 지능형 비행 제어 시스템(IFCS ; Intelligent Flight Control System)까지 개발되어 차세대 비행 제어 시스템 으로 부각되고 있다[12]. 이러한 항공기 제어 시 스템 및 기술 등은 비행 성능을 극대화하고 안정 적인 제어를 가능하게 하여 유사시 발생할 수 있 는 사고를 최소화하고 있다.

하지만, 2000년부터 2009년까지 지난 10년간 총 150 건의 헬리콥터(24건) 및 항공기(126건) 사 고 중 비행장 및 비행장 부근 등의 사고는 128 건 이나 차지하고 있다. 사고 현장을 세부적인 장소 로 구분하면 비행장 및 이착륙장 등에서의 사고 빈도가 $50 \%$ 를 나타내고 있다[14]. 이러한 자료를 
통해 항공기 사고가 비행 중에만 발생하지 않고, 오히려 이착륙 시 발생하는 빈도가 높은 사고라 는 것을 알 수 있다.

Table 1. 2000년부터 2009년까지 항공기 사고 지역별 빈도[14]

\begin{tabular}{|c|c|c|c|c|}
\hline 구분 & 총 & 비행장 & 이착륙장 등 & 공항 및 인근 \\
\hline 빈도수 & 150 & 8 & 67 & 75 \\
\hline
\end{tabular}

이에 대한 원인은 여러 가지 요인이 있을 수 있다. 천재지변과 같은 환경적인 요인, 기계 및 전자 장치나 소프트웨어의 결함과 같은 항공기 자체의 내부 요인, 그리고 관제사, 항공기 조종사 와 같은 인적 요인(human factor)에 의한 부분 등이 원인에 해당될 것이다. 특히, 근래 항공사고 의 $70 \%$ 이상을 차지하는 인적 요인 중 조종사의 경우 항공기의 이착륙 시 조종 장치의 조작 실수 및 계기 판독 시 착오 등이 이에 해당 될 수 있다.

이러한 항공기 사고의 큰 비중을 차지하는 인 적 요인에 의한 사고를 최소화하고 안정적인 비 행을 가능하게 하기 위해 본 논문은 자동비행제 어 기술 중 착륙 시 활주로(runway)에 일직선상 으로 항공기를 유도할 수 있는 횡방향 제어 기술 에 대해 다루고 있다. 이를 위해 항공기의 자세 를 변화시키고 빠른 시간 안에 수평비행상태로 복 귀하기 위해 축소차수 상태관측기를 적용하였다.

본 논문은 다음과 같은 구성을 이루고 있다. 먼저 피장에서는 항공기의 자동 착륙 시스템 구 조와 횡방향 제어를 위한 동역학 식을 소개하고 있으며, III장에서는 축소차수 상태관측기 설계 및 이득행렬(gain matrix) 선정, 그리고 $\mathrm{IV}$ 장은 시뮬레이션 결과를 통한 각 상태들의 수렴 추이 를 보이고 있다.

\section{II. 항공기의 자동착륙시스템 및 횡방향 동역학}

\section{1 자동착륙 및 횡방향 제어 시스템}

항공기의 자동착륙 시스템은 항공기를 제외하고 크게 레이더, 제어부, 송신부로 나뉠 수 있다[1]. 레이더의 경우 공항으로 접근하는 항공기를 감지 하여 비행장으로 유도하는 접근관제레이더인 ASR/SSR(Airport Surveillance Radar/Secondary Surveillance Radar)이 이용되고, 항공기를 활주 로의 최종 착륙단계까지 유도하기 위해 PAR
(Precision Approach Radar)이 이용되거나 관제 사의 지원 없이 조종사가 계기를 이용하여 착륙 하는 ILS(Instrument Landing System) 등이 이용 되기도 한다.

이러한 각종 관제레이더에 의해 항공기의 위 치를 파악하여 제어부를 통한 수치연산이 이루어 지고 송신부를 통해 항공기 조종사에게 현재 항 공기의 횡방향 및 수직 위치 등이 제공될 경우 정밀 착륙을 위한 하나의 방안이 될 수 있다.

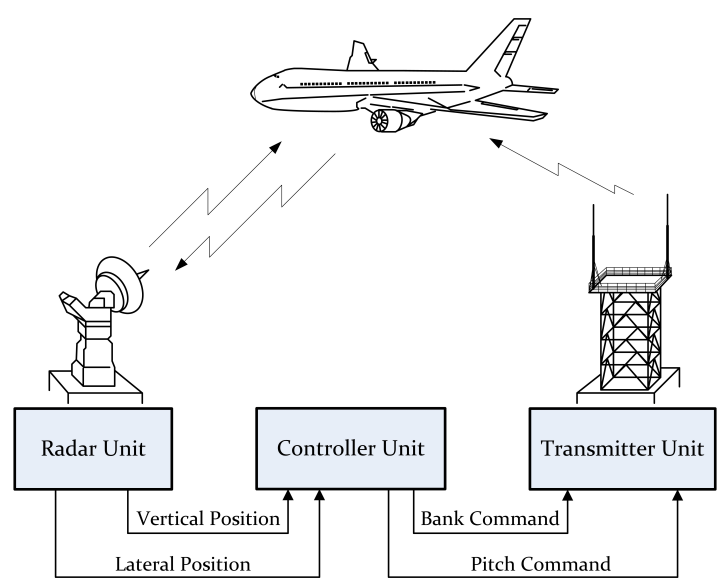

Fig 1. 항공기 자동착륙시스템 개념도

그러므로 조종사는 착륙을 위해 항공기의 탑 재장비를 통해 활주로 중앙선(runway center line) 정보인 Horizontal Information Guidance와 착륙 지대(TDZ ; TouchDown Zone)까지의 각도(glide slope) 정보인 Vertical Guidance 정보를 제공받게 된다.

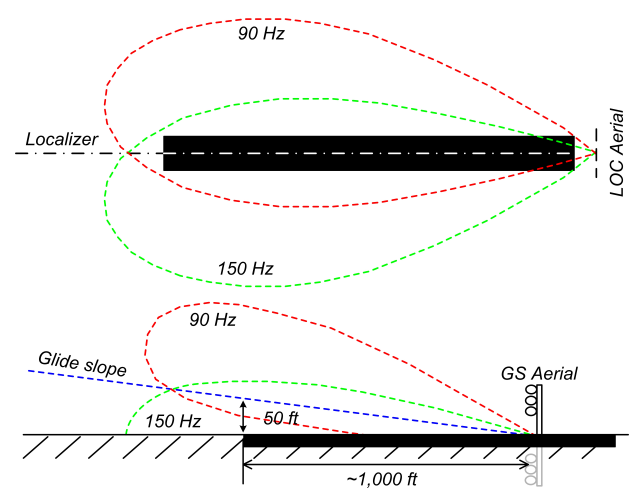

Fig 2. Guidance 방사 패턴[17]

본 논문에서는 항공기 자동착륙 시 활주로의 중앙선을 기준으로 수평적인 횡방향에 대한 제어 
를 다루고 있다. 이 때 pitch command는 고려하 지 않고 항공기의 자세변화를 위해 적용되는 조 정면 중 갸웃각을 조정하는 보조날개인 에일러론 (aileron)과 도리각(yaw)을 조정하는 수직방향판 인 러더(rudder)의 움직임으로 그림 3 에서 볼 수 있듯이 항공기의 착륙 시점 전까지 $L \approx 0$ 이 되 도록 항공기를 활주로 선상에 위치시키는 비행제 어를 다룬다.
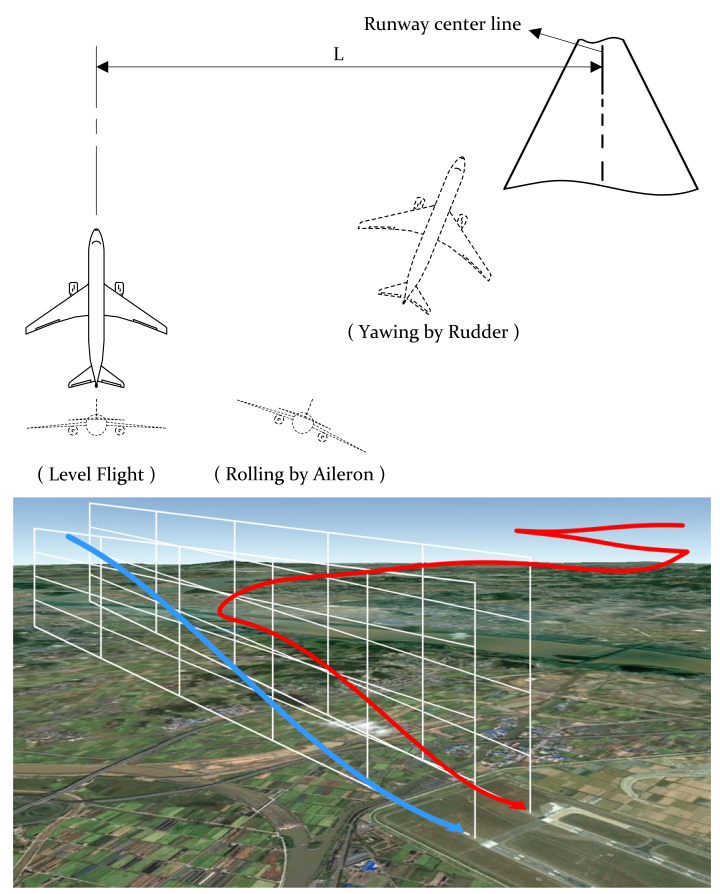

Fig 3. 횡방향 제어 개념도

\section{2 항공기 횡방향 동역학 모델링}

항공기의 수학적 모델링을 위해서 적절한 좌표 계 선정이 선행되어야 한다. 이를 위해 뉴턴의 운동 제 1 법칙이 성립하는 좌표계로 관성좌표계(inertial frame)에 대한 상대적인 운동을 묘사하기 위한 기 준좌표계(reference frame)가 필요하다. 또한, 기준좌 표계에 대해 회전하는 동체좌표계(body frame)를 통해 항공기의 운동에 대한 기술이 가능하다[6].

본 논문에서는 항공기의 횡방향에 대한 적절한 모델링을 위해 기준좌표계로 바람좌표계(wind frame)를 선택하였다[7]. 바람좌표계는 동체좌표 계와 그 축을 공유하는데 단지 $x$ 축 즉 항공기의 세로축이 속도벡터와 일치하게 된다[8]. 여기에 서, 바람과 항공기의 세로축이 이루는 옆미끄러 짐각(sideslip angle)인 $\beta$ 를 $\beta \approx 0$ 으로 가정할
때, 그 좌표계를 안정화좌표계(stability frame)라 한다. 이들 좌표계에 대한 표현은 아래 그림 4 와 같이 나타난다[4][8].

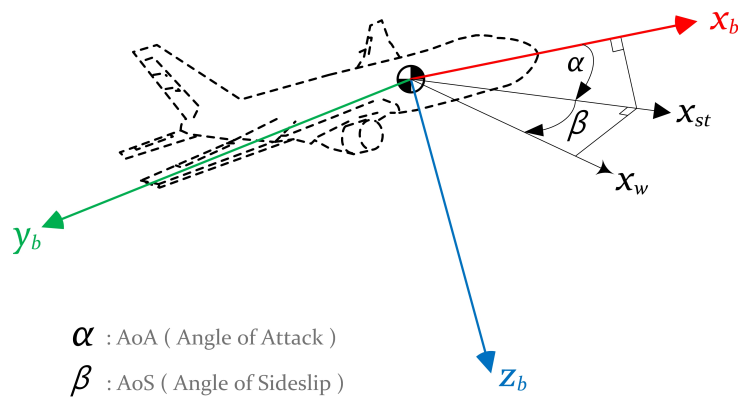

Fig 4. 안정화 및 바람 좌표계에서의 항공기[4]

항공기의 횡방향 제어가 aileron과 rudder 조정 면의 변위(deflection)로 이루어질 때, 항공기의 횡방향 동역학식(lateral direction dynamics)은 상태 벡터(state vector) $\quad x=\left[\begin{array}{llll}v & r & p & \phi\end{array}\right]^{T}$ 와 입력벡터 (input vector) $u=\left[\begin{array}{ll}\delta_{A} & \delta_{R}\end{array}\right]^{T}$ 로 이루어진 상태방 정식(state equation)으로 표현될 수 있다. 각 상 태벡터와 입력벡터를 이루는 상태변수 및 입력변 수들의 설명은 표 2 와 같다.

Table 2. 상태변수 및 입력변수 표기법

\begin{tabular}{|c|c|c|}
\hline 변 수 & 의 미 & 단 위 \\
\hline$v$ & 항공기의 횡방향 속도 & $\mathrm{m} / \mathrm{s}$ \\
\hline$r$ & 동체좌표계에서의 도리각속도 & $\mathrm{deg} / \mathrm{s}$ \\
\hline$p$ & 동체좌표계에서의 갸웃각속도 & $\mathrm{deg} / \mathrm{s}$ \\
\hline$\phi$ & 관성좌표계에 대한 동체축의 갸웃각 & $\mathrm{deg}$ \\
\hline$\delta_{A}$ & 보조날개 각 변위 & $\mathrm{deg}$ \\
\hline$\delta_{R}$ & 수직방향판 각 변위 & $\mathrm{deg}$ \\
\hline
\end{tabular}

표 2에서 상태변수 $v$ 는 바람이 없을 시 옆미 끄러짐각 $\beta=\sin ^{-1}(v / V)$ 로 대체할 수 있다[9]. $\beta$ 를 나타내는 식에서 $V$ 는 항공기의 대기속력 (airspeed)를 나타낸다. 그러므로 상태벡터는 다시 $x=\left[\begin{array}{llll}\beta & r & p & \phi\end{array}\right]^{T}$ 로 대체할 수 있게 된다.

이러한 상태변수와 입력변수를 이용하여 평형조 건(equilibrium trim condition)에서 작은 섭동 
(small perturbation)을 바람좌표계에서 묘사하는 항공기 횡방향 동역학식은 아래 상태방정식으로 표현된다[10].

$$
\left[\begin{array}{c}
\dot{\beta} \\
\dot{r} \\
\dot{p} \\
\dot{\phi}
\end{array}\right]=\left[\begin{array}{cccc}
y_{\beta} & y_{r} & y_{p} & y_{\phi} \\
n_{\beta} & n_{r} & n_{p} & n_{\phi} \\
l_{\beta} & l_{r} & l_{p} & l_{\phi} \\
0 & 1 & 0 & 0
\end{array}\right]\left[\begin{array}{c}
\beta \\
r \\
p \\
\phi
\end{array}\right]+\left[\begin{array}{cc}
y_{\delta_{A}} & y_{\delta_{R}} \\
n_{\delta_{A}} & n_{\delta_{R}} \\
l_{\delta_{A}} & l_{\delta_{R}} \\
0 & 0
\end{array}\right]\left[\begin{array}{l}
\delta_{A} \\
\delta_{R}
\end{array}\right]
$$

식 (1)에서 행렬들의 원소들은 항공기의 대기 속력, 무게, 마하수(Mach number), 고도 등의 값 뿐만 아니라 $y_{\beta}, y_{r}, y_{p}, y_{\phi}$ 는 각각 항공기의 횡방향 속도 $(v)$, 동체좌표계에서의 $\operatorname{roll} \operatorname{rate}(p), \operatorname{yaw} \operatorname{rate}(r)$, 관성좌표계에 대한 동체축(body axes)의 $\operatorname{roll}(\phi)$ 에 의한 lateral force를 포함하고 있으며, $n_{\beta}, n_{r}, n_{p}, n_{\phi}$ 는 yaw moment를, $l_{\beta}, l_{r}, l_{p}, l_{\phi}$ 는 roll moment를 각각 포함하는 무차원(dimensionless)값을 나타내 고 있다.

또한, $y_{\delta_{A}}, y_{\delta_{R}}$ 와 $n_{\delta_{A}}, n_{\delta_{R}}$ 그리고 $l_{\delta_{A}}, l_{\delta_{R}}$ 는 항공 기의 보조날개인 aileron의 각변위 $\delta_{A}$ 와 수직방 향판인 rudder의 각변위 $\delta_{R}$ 에 의한 항공기의 lateral force, yaw moment, roll moment를 포함하는 무 차원 값이다.

\section{III. 축소차수 상태관측기}

\section{1 축소차수 상태관측기 설계}

시스템의 상태벡터(state vector)를 재구성하는 장치인 관측기(observer) 설계에 있어 축소차수 상태관측기(ROLSO ; Reduced Order Luenberger State Observer)는 측정할 수 없는 부분의 상태 변수를 추정하는 관측기이다[2][3]. 상태벡터는 앞서 항공기의 횡방향 동역학식을 통해 알 수 있 듯이 $x=\left[\begin{array}{llll}\beta & r & p & \phi\end{array}\right]^{T}$ 로 정의하였다. 이 때, GPS 신호와 항공기 등에 탑재된 지자기 센서 및 풍속센서(wind speed sensor)를 이용하여 항공기 의 목표 경로와 실제 경로와의 차이를 통해 각각 옆미끄러짐각과 동체좌표계에서의 도리각속도(yaw rate)인 $\beta$ 와 $r$ 을 참값에 매우 근사하게 측정할 수 있다고 가정한다. 이러한 가정은 점차 정확성 이 높아지는 GPS 신호 및 그 신호의 처리 기술 과 지자기 센서 및 각종 센서들의 성능 향상으로 가능할 것으로 판단된다.

GPS 신호는 SA(Selective Availability)라고 하 는 민간용 신호에 의도적인 에러코드를 함께 송 출하여 $100 \mathrm{~m}$ 내외의 수직 및 수평 오차를 발생
시킨 제한을 2000년 5월 2일부로 해제한 이후 위 치오차가 $10 \mathrm{~m}$ 내외로 신호의 정확도(accuracy)가 크게 향상되어 항법시스템 성능 향상의 활용도가 높아지고 있으며, 특히 반송파 기반의 CDGPS 기술 및 GPS 신호 오차 보정시스템인 GBAS(Ground Based Augmentation System)와 SBAS(Satellite Based Augmentation System)의 도입과 향후 GPS 위성의 업그레이드를 통해 신호의 정확도는 $1 \mathrm{~m}$ 이하로 한층 더 개선될 전망이다. 특히 GBAS 경우 최종 정밀 착륙 유도를 위해 우리나 라에서도 운용될 가능성이 높은 지상 보강시스템 이다. 또한 지자기 센서는 항공기가 지향하는 방 위각을 알 수 있게 하고, 풍속센서(Wind Speed Sensor)는 항공기의 앙각(AoA ; Angle of Attack)과 옆미끄러짐각(AoS; Angle of Sideslip)을 측정할 수 있도록 한다[13].

이러한 현재의 기술력을 근거로 항공기의 횡 방향 접근 제어를 위한 선형시불변 시스템(Time Invariant System)의 상태방정식 및 출력방정식을 다음과 같이 고려한다.

$$
\begin{aligned}
& \dot{x}=A x+B u \\
& y=C x
\end{aligned}
$$

이 때, $A$ 는 항공기의 횡방향 동역학을 나타내 는 시스템 행렬, $B$ 와 $C$ 는 각각 입력 및 출력행 렬, $x$ 는 항공기 횡방향 동역학식의 상태공간모델 을 나타내는 상태벡터, $y$ 는 출력벡터, $u$ 는 입력 벡터로 정의한다. 이 중 가정을 통해 알고 있는 상태벡터를 $x_{1}=\left[\begin{array}{ll}\beta & r\end{array}\right]^{T}$ 이라 하고, 추정하고자 하는 상태벡터를 $x_{2}=\left[\begin{array}{ll}p & \phi\end{array}\right]^{T}$ 로 정의하면 식 (1)의 상태방정식과 출력방정식은 식 (3)와 같이 분리 가능하다[3]. 식 (2)에서 $I_{2}$ 와 $0_{2}$ 는 $(2 \times 2)$ 크 기의 단위행렬과 영행렬을 나타낸다.

$$
\begin{gathered}
{\left[\begin{array}{c}
\dot{x}_{1} \\
\dot{x}_{2}
\end{array}\right]=\left[\begin{array}{ll}
A_{11} & A_{12} \\
A_{21} & A_{22}
\end{array}\right]\left[\begin{array}{l}
x_{1} \\
x_{2}
\end{array}\right]+\left[\begin{array}{l}
B_{1} \\
B_{2}
\end{array}\right] u} \\
y=\left[\begin{array}{ll}
I_{2} & 0_{2} \\
0_{2} & 0_{2}
\end{array}\right]\left[\begin{array}{l}
x_{1} \\
x_{2}
\end{array}\right]=x_{1}
\end{gathered}
$$

한편, 축소차수 상태관측기의 상태방정식은 식 (3)에서 측정할 수 있는 부분과 측정할 수 없는 부분의 분리 및 상태벡터와 행렬들의 치환을 통 해 식 (4)과 같이 설계된다. 이 때, 식 (4)에서 
$K_{R}$ 은 측정된 출력값과 추정된 출력값의 차이를 조절할 수 있는 이득행렬이며, $\tilde{x}$ 는 추정된 상태 벡터를 의미한다.

$$
\begin{aligned}
\dot{\tilde{x}}= & \left(A_{22}-K_{R} A_{12}\right) \widetilde{x_{2}}+\left(A_{21} x_{1}+B_{2} u\right)+ \\
& K_{R}\left(\dot{x_{1}}-A_{11} x_{1}-B_{1} u\right)
\end{aligned}
$$

하지만, 축소차수 상태관측기의 단점이기도 한 출력의 미분값 $\left(\dot{x}_{1}\right)$ 으로 잘못된 정보가 증폭될 수 있으므로 다른 상태벡터 $q$ 를 사용하여 식 (4)을 다시 표현할 수 있다. 이를 위해 새로운 상태벡 터 $q$ 를 식 (5)와 같이 정의하여 $q$ 에 대한 축소차 수 상태관측기 동역학식을 식 (4)에 적용하여 식 (6)과 같이 만들 수 있다[3].

$$
\begin{aligned}
& q=x_{2}-K_{R} y=x_{2}-K_{R} x_{1} \\
& \dot{\tilde{q}}=\left(A_{22}-K_{R} A_{12}\right) \tilde{q}+\left[\left(A_{11}-K_{R} A_{12}\right) K_{R}+\right. \\
& \left.\left(A_{21}-K_{R} A_{11}\right)\right] x_{1}+\left(B_{2}-K_{R} B_{1}\right) u
\end{aligned}
$$

식(4)의 미분값 $\left(\dot{x_{1}}\right)$ 을 없애기 위해 도입한 상태 벡터 $q$ 의 추정치 $\tilde{q}$ 는 측정을 통해 알 수 있는 상태벡터 $x_{1}$ 과 측정할 수 없어 추정한 상태벡터 $\widetilde{x_{2}}$ 로 이루어 졌으므로 축소차수 상태관측기 설 계를 위해 항공기의 횡방향 제어 시 가정한 $\beta$ 와 $r$ 이 측정 가능할 때 추정된 상태벡터 $\tilde{x}$ 는 식 (7) 과 같이 표현된다.

$$
\tilde{x}=\left[\begin{array}{c}
x_{1} \\
\widetilde{x}_{2}
\end{array}\right]=\left[\begin{array}{c}
O_{2} \\
I_{2}
\end{array}\right]\left[\widetilde{x_{2}}-K_{R} x_{1}\right]+\left[\begin{array}{c}
I_{2} \\
K_{R}
\end{array}\right] x_{1}
$$

이렇게 식 (6)와 식 (7)의 과정을 거쳐 추정된 상태벡터 $\tilde{x}$ 와 적절한 극점배치(pole placement)를 통해 선정된 이득행렬이 곱해진 결과가 다시 입력 에 사용되는 축소차수 상태관측기를 이용한 되먹 임 시스템은 그림 5 와 같은 시스템을 이루고 있 다. 그림 5 에서 $\bar{A}, \bar{B}, \bar{N}$ 는 식 (6)의 행렬 관련 식을 간결하게 정리하기 위해 $\left(A_{22}-K_{R} A_{12}\right) \rightarrow \bar{A}$, $\left(\bar{A} K_{R}+A_{21}-K_{R} A_{11}\right) \rightarrow \bar{B}, \quad\left(B_{2}-K_{R} B_{1}\right) \rightarrow \bar{N}$ 로 정의하였으며, 식 (6)은 식 (8)과 같이 간결한 형태가 된다.

$$
\dot{\tilde{q}}=\bar{A} \tilde{q}+\bar{B} x_{1}+\bar{N} u
$$

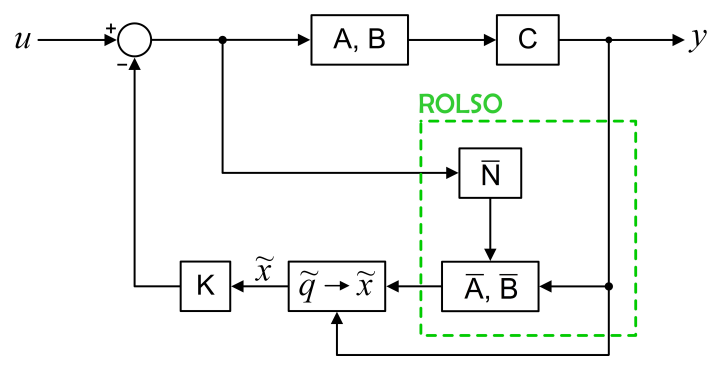

Fig 5. ROLSO를 이용한 되먹임 시스템

\section{2 이득행렬 선정}

축소차수 상태관측기를 이용한 되먹임 시스템 (feedback system)을 구현하기 위해 극점배치 설계와 축소차수 상태관측기의 폐루프 극점을 적절하게 선정한다. 이 때 사용되는 이득행렬은 MATLAB의 Control Toolbox에 있는 내장함수인 place를 사용 하여 구할 수 있다[5].

한편, 항공기의 횡방향 제어에 대한 상태방정 식을 위해 [10]의 고도 $15,000 \mathrm{ft}$ 에서 Mach 0.44 로 비행하는 총 무게 $190,000 \mathrm{lb}$ 의 Douglas DC-8 항 공기 자료를 사용하였다. 이 자료를 이용하여 식 (2)에서의 상태방정식을 나타내면 시스템 행렬인 $A$ 와 입력행렬인 $B$ 는 아래와 같다.

$$
\begin{aligned}
& A=\left[\begin{array}{cccc}
-0.1008 & -468.2 & 0 & 32.2 \\
0.00278 & -0.257 & -0.0346 & 0 \\
-0.00579 & 0.397 & -1.232 & 0 \\
0 & 0 & 1 & 0
\end{array}\right], \\
& B=\left[\begin{array}{cc}
0 & 13.48416 \\
-0.01875 & -0.864 \\
-1.62 & 0.392 \\
0 & 0
\end{array}\right]
\end{aligned}
$$

이 때, 극점배치 설계와 축소차수 상태관측기 의 폐루프 극점 설계 시 사용되는 이득행렬은 각 각 $K$ 와 $K_{R}$ 이라 정의한다. 여기에 되먹임 제어와 축소차수 상태관측기의 극점을 각각 $S_{K}$ 와 $S_{K_{R}}$ 이 라 하고, 적절한 값들을 아래와 같이 선정하였다.

$$
\begin{aligned}
& S_{K}=\left[\begin{array}{llll}
-27+3 \sqrt{2} i & -27-3 \sqrt{2} i & -5 & -30
\end{array}\right], \\
& S_{K_{R}}=\left[\begin{array}{ll}
-195 & -195
\end{array}\right]
\end{aligned}
$$


또한, 이득 행렬을 구하면 $K$ 와 $K_{R}$ 의 값은 다 음과 같다.

$$
\begin{aligned}
K & =\left[\begin{array}{lllr}
2.6523 & -8.3542 & -19.33 & -84.835 \\
1.9242 & -34.568 & 0.32307 & 3.7664
\end{array}\right], \\
K_{R} & =\left[\begin{array}{cc}
0 & -5600.2 \\
6.0559 & -28.902
\end{array}\right]
\end{aligned}
$$

\section{IV. 시뮬레이션 결과}

항공기의 횡방향 제어에 대한 모의실험을 위해 앞서 설명한 바와 같이 GPS 신호와 지자기센서 나 풍속센서와 같은 보조센서의 정보를 통해 옆 미끄러짐각 $\beta$ 와 동체좌표계 상에서의 도리각속도 $r$ 이 측정가능하고 항공기의 동체좌표계에 대한 갸웃각속도인 $\operatorname{roll} \operatorname{rate}(p)$ 와 관성좌표계에 대한 동체축의 갸웃각인 roll angle $(\phi)$ 을 측정할 수 없 다는 가정 하에 축소차수 상태관측을 통한 되먹 임 제어 시 각 상태벡터들의 원소인 상태변수 값 들의 추이를 살펴보았다. 이 때, 상태벡터인 $x$ 의 초기값을 다음과 같이 설정하였다.

$$
\left[\begin{array}{llll}
\beta & r & p & \phi
\end{array}\right]=\left[\begin{array}{llll}
10 & 35 & 10 & 5
\end{array}\right]
$$

즉, 옆미끄러짐각은 $10(\mathrm{deg})$, 동체좌표계 상에 서의 도리각속도와 갸웃각속도는 각각 $35(\mathrm{deg} / \mathrm{s})$, $10(\mathrm{deg} / \mathrm{s})$, 그리고 관성좌표계에 대한 동체축의 갸웃각은 $5(\mathrm{deg})$ 로 설정하여 각 상태변수들의 추 이를 MATLAB을 통하여 다음과 같은 결과를 보 이고 있다.

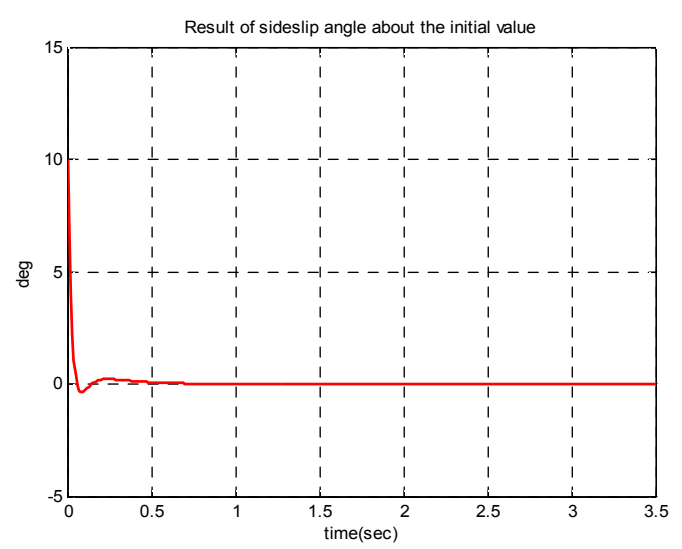

Fig 6. 초기값에 대한 $\beta$ 상태 추이

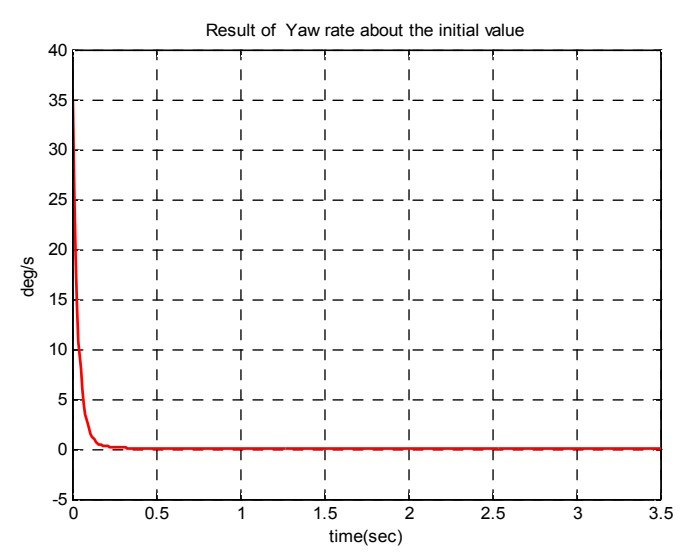

Fig 7. 초기값에 대한 $r$ 상태 추이

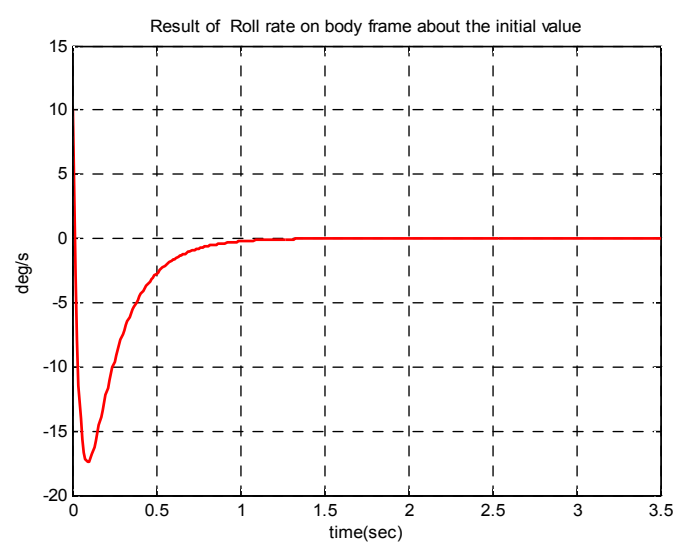

$\mathrm{Fig}$ 8. 초기값에 대한 $p$ 상태 추이

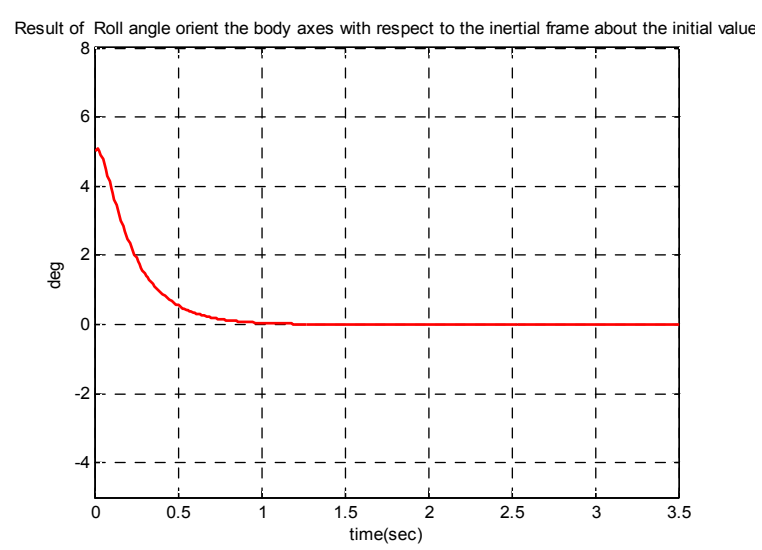

Fig 9. 초기값에 대한 $\phi$ 상태 추이 
그림 6 9를 통해 상태변수 $\beta, r, p, \phi$ 의 시간에 따른 상태 변화를 살펴보았다. 결과적으로 모든 상태변수들이 1 초안에 “ 0 " 값 근처로 수렴함을 볼 수 있다.

한편, 대부분 항공기의 운항속도(operating speed)가 고고도에서 Mach 0.8 0.92이며, 약 30,000ft이하의 저고도에서 330 360KIAS(Knots Indicator Air Speed) 의 속도제한을 정하고 있다. 이러한 점을 고려하여 그림 10 에서와 같이 저고도에서 최대 운항속도를 의 미하는 $\mathrm{VMO}$ (Maximum Operating Speed)가 350KIAS (약 $650 \mathrm{Km} / \mathrm{h}$ )인 $\mathrm{B} 757$ 항공기의 경우 착륙을 위한 횡방향 속도를 $\mathrm{VMO}$ 의 $40 \%$ 수준인 $260 \mathrm{Km} / \mathrm{h}$ 로 가정하여 항공기가 착륙 시 활주로 중앙선상으로 비행하기 위해 축소차수 상태관측기를 이용한 되 먹임 제어 시스템을 적용할 수 있다.

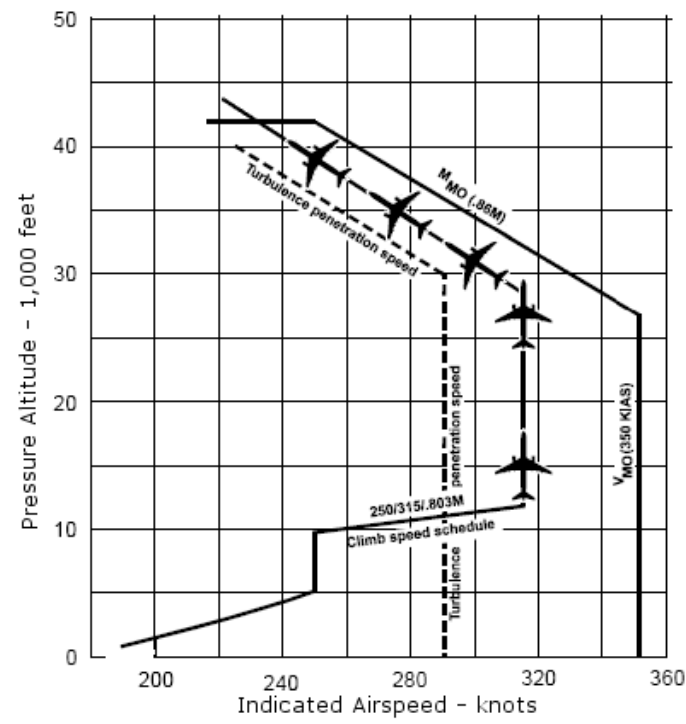

Fig 10. B757의 $\mathrm{VMO}$ 및 $\mathrm{MMO}[11]$

이를 위해 $\mathrm{IV}$ 장에서 사용된 시뮬레이션 초기 값이 주어졌을 때 $260 \mathrm{Km} / \mathrm{h}$ 의 횡방향 속력을 갖 는 항공기는 시뮬레이션 결과로 비추어 볼 때 1 초간 이동거리 즉 약 $72 \mathrm{~m}$ 의 횡방향 이동 범위 내에 안정적인 수평비행을 유지시킬 수 있게 된 다. 이를 통해 공역 상에서 비교적 작은 횡방향 이동거리로 활주로 선상의 위치제어가 가능할 수 있음을 예상할 수 있다.

\section{V. 결 론}

항공기의 안전한 운항을 위해 많은 시스템이
개발되어 있고, 많은 정보를 이용하고 있다[15][16]. 하지만 항공기가 착륙 시 관제사나 조종사가 원 하는 방향으로 제어되지 않는다면 여전히 항공기 사고 중 이착륙 시 발생하는 사고가 감소되지 않 을 것이다. 이에 본 논문은 자동착륙 시 항공기 의 횡방향에 대한 비행 제어를 다루었으며, 이 때 사용된 상태변수들이 초기값 설정 후 얼마나 빨리 안정한 수평상태를 유지하게 되는지 살펴보 았다.

향후, 본 논문에서 보인바와 같이 횡방향에 대 한 상태변수들의 안정화를 위한 제어뿐만 아니라 공항 근처의 공역에 항공기 접근 시 축소차수 상 태관측기와 다른 제어기법을 통해 착륙까지의 각 위치 별 항공기 자세 변화에 대한 추이를 분석하 여 안전한 자동 착륙시스템에 적용할 수 있는 기 법을 연구할 필요가 있다.

또한, 잡음(noise)을 고려한 noisy system에서 많이 사용하는 칼만필터(Kalman Filter)와의 성능 비교를 통해 항공기 자동착륙 시스템에 적용하는 것과 지상에서 항공기에 정보를 제공하기 위한 효율적인 데이터 링크의 활용 방안 등에 대한 연 구도 필요하다고 판단된다.

\section{후 기}

본 연구는 기초기술연구회의 "재난예방 및 국민 안전제고를 위한 위성기반 위치추적기술 연구"과 제의 일환으로 수행되었으며 지원에 감사드립니다.

\section{참고문헌}

[1] Charles L. Phillips, H. Troy Nagle, "Digital Control System Analysis and Design 3rd", Prentice Hall, 1995, pp.3 6.

[2] D. G. Luenberger, "Observing the State of a Linear system", IEEE Transactions on Military Electronics, Vol. 8, Issue 2, April 1964, pp.74 80.

[3] Katsuhiko Ogata, "Modern Control Engineering, 2nd Ed., Prentice Hall Inc., 1990, pp.795 821.

[4] Mark Peters, Michael A. Konyak, "The Engineering Analysis and Design of the Aircraft Dynamics Model for The FAA Target Generation Facility", Federal Aviation Administration, November 2003, pp.9 17.

[5] J. Kautsky, N. K. Nichols and P. Van Dooren, "Robust Pole Assignment in Linear 
State Feedback", IEEE Transactions on Control System Technology, Vol. 18, No. 2, March 2010, pp.1129 1155 .

[6] I. K. Peddle, "Acceleration Based Maneuvre Flight Control System for Unmanned Aerial Vehicles", University of Stellenbosch, Dec. 2008, pp.10

[7] I. K. Peddle, T. Jones, "Acceleration Based 3D Maneuver Flight Control System for UAVs : Strategy and Longitudinal Design", Automatica, January 2008

[8] Deon Blaauw, "Flight Control System for a Variable Stability Blended-Wing-Body Unmanned Aerial Vehicle", University of Stellenbosch, March 2009, pp.6 8.

[9] Robert F. Stengel, "Flight Dynamics", Princeton University Press, 2004, pp.575

[10] M. V. Cook, "Flight Dynamics Principles", Arnold, 1997, pp.145 147.

[11] Boeing Commercial Airplane Group, "Vmo/Mmo LIMIATATIONS REVIEW", January 08, 1999

[12] M. G. Perhinschi, J. Burken, M. R. Napolitano, G. Campa, M. L. Fravolini, "Performance Comparison of Different Neural Augmentation for the NASA Gen_2 IFCS F-15 Control Laws", American Control Conference, June 2004, pp.3180 3184 .

[13] X. Q. Chen, Q. Ou, D. R. Wong, Y. J. Li, M. Sinclair, A. Marburg, "Flight Dynamics Modelling and Experimental Validation for Unmanned Aerial Vehicles", May 2009, pp.17 7 202 .

[14] 권병모, “국내 항공기 사고 발생 유형과 원 인에 대한 실증 분석", 한국항공대학교 석사학위 논문, 8월 2011년, pp.48 51.

[15] 남기욱, 허문범, 심주영, “위성항법시스템 및 보강시스템의 구축 현황", 항공우주산업기술동향 5권 1호, 2007, pp.65 74.

[16] 전향식, 김동민, 염찬홍, "차세대 항행시스템 (CNS/ATM) 기술 동향 분석", 항공우주산업기술 동향 8권 2호, 2010, pp.113 123.

[17] http://en.wikipedia.org/wiki/Instrument_la nding_system 